hospitalization was performed $(n=14)$. The first group included 6 patients who retained low disease activity during 1 month follow-up (RA, stabilization). The second group consisted of 8 patients who had exacerbation during follow-up period. As a control group, we used data from 43 comparable healthy donors. Subsets of $\mathrm{T}$ regulatory cells and monocytes were studied. A comparison was made among the indicators of receptors number and proportion of cells expressing the corresponding receptor.

Results: For T regulatory cells, the key differences for patients who did not retain low disease activity were significantly higher number of TNF type 1 and type 2 receptors on double-positive cells with a lower percentage of these cells compared to stable patients. At the same time, higher differences between proportions of double-positive cells in comparison with control values of healthy donors were associated with higher probability of maintaining in remission.

For monocytes, the key differences in stable patients were the very high quantitative expression of type 1 receptors on double-positive cells, with a lower percentage of these cells compared to patients with exacerbation. At the same time, lower differences between proportions of double-positive cells in comparison with control values of healthy donors were associated with higher probability of maintaining in remission.
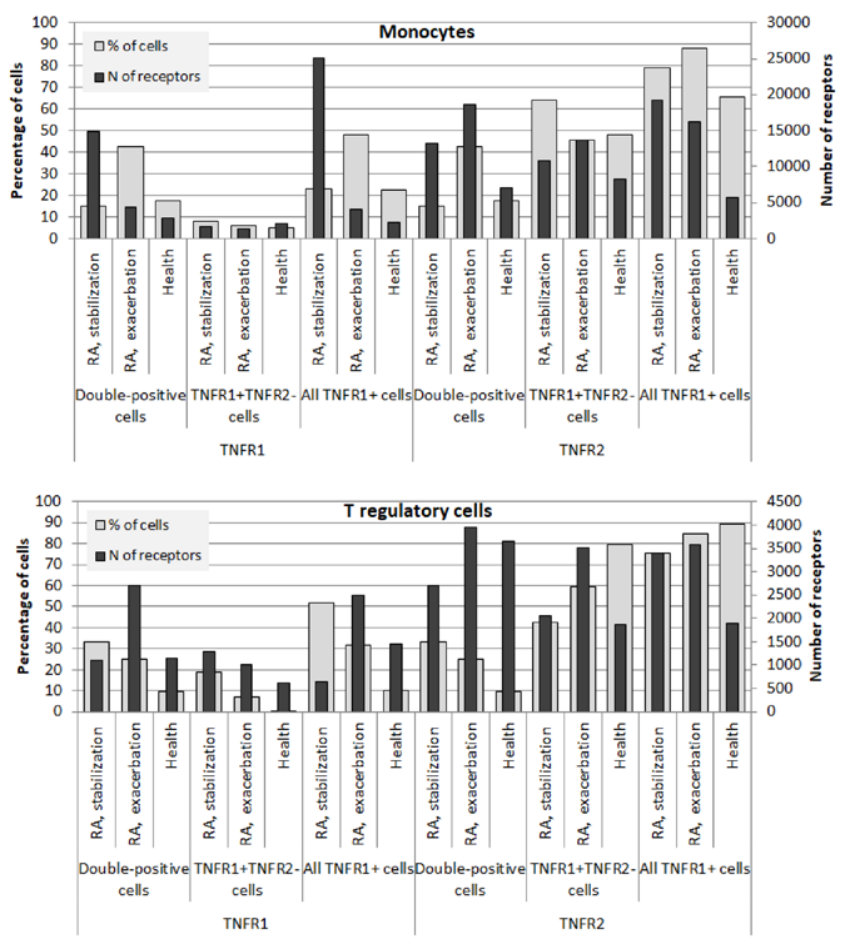

Conclusion: Obtained data confirm the previously proposed hypothesis about the essential role of balance in quantitative expression of TNF receptors type 1 and 2 on double-positive cells to determine the intensity and type of cell response to the mediator and its association with the level of disease activity and response to therapy.

Acknowledgements: This study is supported by grant of the President of the Russian Federation for state support of young Russian PhD scientists №MK-2433.2020.4 Disclosure of Interests: None declared

DOI: 10.1136/annrheumdis-2021-eular.3873

\section{POS0501 SUSTAINED 2-YEAR REMISSION OF THE DISEASE IN A CLINIC OF EXCELLENCE IN RHEUMATOID ARTHRITIS. EXPERIENCE OF THE CLINICAL REGISTRY IN COLOMBIA}

J. M. Bello-Gualtero ${ }^{1,2}$, E. Peña ${ }^{3}$, P. I. Santos Moreno ${ }^{4}$, J. Vesga Gualdrón ${ }^{3}$, G. Saavedra ${ }^{5}$, C. Perez ${ }^{6}$ on behalf of Grupo Inmunología Clínica Aplicada de la Universidad Militar Nueva Granada. ${ }^{1}$ Hospital Militar Central, Rheumatology and Immunology, Bogotá, Colombia; ${ }^{2}$ Universidad Militar Nueva Granada, Grupo Inmunología Clínica Aplicada, Bogotá, Colombia; ${ }^{3}$ Pontificia Universidad Javeriana, Health Economics, Bogotá, Colombia; ${ }^{4}$ BIOMAB IPS, Rheumatology, Bogotá, Colombia; ${ }^{5}$ Hospital Militar Central, Epidemiology, Bogotá, Colombia; ${ }^{6}$ Hospital Militar Central, Cuenta de alto costo, Bogotá, Colombia

Background: Rheumatoid arthritis (RA) is a chronic autoimmune disease with no cure, characterized by episodes of exacerbation and remission, which requires permanent use of medications. Clinics of excellence are multidisciplinary and centralized programs that improve adherence to treatments. Information on the benefits of these models of care has been published but is not definitive. In Colombia, the clinical registry of patients with RA is kept in the Cuenta de Alto Costo (CAC) Objectives: To demonstrate the difference in the percentages of sustained remission at 2 years, between an institution with non-centralized management or standard of care (Hospital Militar Central-HMC) compared to another institution with centralized management or clinic of excellence (BIOMAB-IPS) and determine if the results are determined by any of the intervention variables or by the program.

Methods: The 2-year clinical records for the CAC were compared between an institution with non-centralized management $(\mathrm{HMC})$ in comparison with another institution with centralized management (BIOMAB-IPS), performing a sociodemographic description, measuring control of the disease DAS28 clinimetry, Fisher's test non-parametric bivariate analysis, multiple regression model, and population matching with Propensity score Matching (PSM).

Results: Complete information was obtained from 2 years of follow-up, in centralized management 3457 patients and for the non-centralized unit 114 patients. Most of them corresponded to 2962 women (82\%), with time of illness of 9.5 years and 10.2 years, respectively, without statistically significant differences. A difference was observed in the 2 programs to maintain remission at 2 years, in favor of the centralized program $54.7 \%$ vs $28.6 .2 \%(p<0.00)$. With the binomial generalized linear regression model, it was confirmed that this difference was not explained by variables such as the use of biological therapy $(R R=0.77 ; 95 \%$ $\mathrm{Cl} 0.69-0.86)$, use of DMARDs (RR $=0.71 ; 95 \% \mathrm{Cl} 0.62-0.82)$ and number of rheumatology consultations $(\mathrm{RR}=0.97 ; 95 \% \mathrm{Cl} 0.92-1.02)$ in comparison with the centralized care model $(R R=2.32 ; 95 \% \mathrm{Cl} 1.58-3.35)$. Due to the biases between the groups due to the non-probability sampling, a PSM was performed, with a $1: 1$ match, caliper of 0.065 , obtaining a pseudo population with well-balanced covariates (see table 1 ). In the common support area, statistically significant differences were documented in sustained remission over 2 years, in favor of the centralized care group 45 vs $17.9 \%(p=0.001)$.

Conclusion: With the information from the clinical records, statistical strategies can be used to evaluate important differences in centralized care programs, observing favorable results of these types of care that are not related to isolated elements of the program, but to the overall effect of the program.

\section{REFERENCES:}

[1] Austin PC. Double propensity-score adjustment: A solution to design bias or bias due to incomplete matching. Stat Methods Med Res. 2017;26(1):201-22.33333

Disclosure of Interests: Juan Manuel Bello-Gualtero: None declared, Esperanza Peña: None declared, Pedro Iván Santos Moreno: None declared, Jasmin Vesga Gualdrón Employee of: Baxter, Ginna Saavedra: None declared, Clara Perez: None declared DOI: 10.1136/annrheumdis-2021-eular.3886

\section{\begin{tabular}{|l|l}
\hline POS0502 & WHAT IS THE ROLE OF VITAMIN D STATUS IN
\end{tabular} DISEASE ACTIVITY IN RHEUMATOID ARTHRITIS PATIENTS TREATED WITH bDMARDs? - DATA FROM A RHEUMATOLOGY CENTER}

D. Fonseca ${ }^{1}$, M. Rato ${ }^{2}$, F. Oliveira Pinheiro ${ }^{2}$, B. M. Fernandes ${ }^{2}$, S. Garcia ${ }^{2}$, A. Martins ${ }^{2}$, D. Santos Oliveira ${ }^{2,3}$, F. R. Martins ${ }^{4}$, M. Bernardes ${ }^{2,5}$, L. Costa ${ }^{2}$ ${ }^{1}$ Centro Hospitalar de Vila Nova de Gaia / Espinho, Rheumatology, Vila Nova de Gaia, Portugal; ' Centro Hospitalar Universitário de São João, Rheumatology, Porto, Portugal: ${ }^{3}$ Center for Health Technology and Services Research (CINTESIS), University of Porto, Faculty of Medicine, Porto, Portugal; ${ }^{4}$ Centro Hospitalar Universitário do Algarve, Rheumatology, Faro, Portugal; ${ }^{5}$ Faculdade de Medicina da Universidade do Porto (FMUP), Rheumatology, Porto, Portugal

Background: Vitamin D is a fat-soluble vitamin, mainly involved in the regulation of calcium metabolism, and it has gained increasing interest in recent years because of its potential role in immunomodulatory activity. Recent data suggest that it is negatively associated with disease activity in rheumatoid arthritis (RA), however this is not yet fully understood.

Objectives: This study's aim was to investigate if there is any correlation between vitamin $D$ serum levels at baseline, before taking the first biological disease-modifying antirheumatic drug (bDMARD), and at 6 months after, with disease activity in a cohort of RA patients.

Methods: This is a cross-sectional study, including all the rheumatoid arthritis patients taking the first bDMARD with evaluation of the vitamin D status at baseline and 6 months after biologic therapy at our Rheumatology Department and registered in the national database (Reuma.pt).

Demographic, clinical and laboratorial characteristics and disease activity measures were collected from the baseline visit and the visit after 6 months of treatment with the first biologic. For the statistical analysis, two groups were defined, based on the serum levels of $25(\mathrm{OH})$ vitamin $\mathrm{D}$, considering the most common cut-off of $30 \mathrm{ng} / \mathrm{mL}$. For comparison analyses between groups, chi-square test was used for categorical variables and Mann-Whitney $U$ and T-tests were applied for continuous variables. 